\title{
Relationship between Common Dietary Polyphenols and Obesity-Induced Inflammation
}

\author{
Lada Tucakovic*, Natalie Colson, Indu Singh
}

School of Medical Science, Griffith University, Parklands Drive, Qld, Australia

\begin{abstract}
The incidence of obesity and its related metabolic disorders has escalated dramatically in the past decades worldwide. Defined as abnormal or excessive fat accumulation caused by an imbalance between energy intake and expenditure, obesity is presently the major health challenge in developed countries and the causative factor of numerous diseases such as heart problems, hypertension, hyperlipidemia and type 2 diabetes. Presence of high level of cytokines and acute phase proteins associated with inflammation in obese individuals relates obesity to chronic low-grade inflammation. Obesity-induced inflammation has an impact on insulin resistance and cardiac health. Polyphenols including catechins, tocopherols, resveratrol, curcumin and anthocyanins have been shown to reduce adipose tissue inflammation. It has been broadly accepted that adipocyte dysfunction plays a major role in development of obesity and obesity related complications. This state is characterised by hypersecretion of pro-atherogenic, pro-inflammatory and pro-diabetic adipokines as well as decreased secretion of adiponectin. The dietary polyphenols described in this review have potential as nutritional strategies for the prevention of obesity and associated inflammation as well as increase in insulin sensitivity in diabetic people.
\end{abstract}

Keywords Obesity, Obesity-Induced inflammation, Adipose tissue dysfunction, Dietary intervention, Polyphenols

\section{Introduction}

The incidence of obesity and its related metabolic disorders has escalated dramatically in the past decades worldwide reaching epidemic proportions and becoming a key public health issue with a massive burden to the health-care system $[1,2]$. It is not that just the high-income countries are affected with this condition, obesity is a worrying escalation in developing countries as well $[1,2]$. In 2008 the World Health Organisation estimated that globally 1.5 billion $>20$ years old adults were overweight and 200 million men and nearly 300 million women were obese. Overall, more than one in ten of the world's adult population is obese. Statistically, obesity is the fifth leading risk for human mortality around the globe resulting in 2.8 million adult deaths each year [3]. Furthermore, $44 \%$ of diabetes increase, $23 \%$ of the ischemic heart disease increase and $7-41 \%$ increase of certain cancer is related to the overweight and obesity epidemic [3].

More alarming is that childhood obesity is on upsurge also and it has increased dramatically since 1990 [4]. Globally, in 2010, 43 million children were estimated to be overweight and obese with 92 million at risk of being overweight [4]. In 2012 , around 44 million $(6.7 \%)$ of the world's children

* Corresponding author:

1.tucakovic@griffith.edu.au (Lada Tucakovic)

Published online at http://journal.sapub.org/fph

Copyright (C) 2015 Scientific \& Academic Publishing. All Rights Reserved aged less than five years were overweight or obese [5]. Overweight children are likely to become obese adults and are more likely than non-overweight children to develop diabetes and cardiovascular diseases (CVDs) at a younger age, which can lead to premature death and disability [5]. Childhood obesity is one of the most serious public health challenges of the 21 st century and it is expected to increase to about 60 million obese children, in 2020 [4].

Obesity is a complex disease controlled by many factors such as genetic, environmental and behavioural [6]. Amongst the environmental factors, the continuing intake of high fats (HF) in the diet is strongly linked with the development of obesity which further can lead to insulin resistance and development of type 2 diabetes [7]. It is linked to an increase in certain type of cancers as well as pulmonary diseases [1].

\subsection{Inflammation, Obesity and Associated Diseases}

It has been accepted for over a decade that obesity is connected with chronic low-grade inflammation $[1,8]$. The basis for this view is that the circulatory levels of several cytokines and acute phase proteins associated with inflammation are increased in obesity. While many of them are secreted by adipocytes it is believed that increased adipose tissue mass is either directly or indirectly associated with increased production of inflammation-related factors [9]. Various cell types contribute to chronic low grade inflammation, which has been suggested to increase adipose tissue mass in metabolic disorders [10]. One of the first 
cytokines to be found elevated in obese mice tissue and the one which links obesity and inflammation was tumour necrosis factor- $\alpha$ (TNF- $\alpha)$ [11]. After that many studies looked at this phenomenon and found that many other cytokines such as interleukin (IL)-6, IL-1 $\beta$ and chemokine (C-C motif) ligand 2 (CCL2) are increased in adipose tissues in obese animals and humans $[12,13]$. Furthermore, it has been shown that not only the adipose tissue but other tissues such as liver, pancreas, brain and probably muscle, also experience increased level of these cytokines and possible insulin resistance in the obese state [14-17]. In other words, the state of inflammation in adipose tissue in obesity plays to an important role in increased production and secretion of inflammation related factors and insulin sensitivity.

Increased adipose tissue has been associated with abnormal lipid and glucose metabolism, hypertension, and inflammation as risk factors of cardiovascular disease, type 2 diabetes, the metabolic syndrome and various cancers. Obesity-induced inflammation and the activation of the innate immune system are closely involved in the pathogenesis of type 2 diabetes and further development of CVDs [18]. There is proven link between obesity related insulin resistance and increased production of tumour necrosis factor- $\alpha$ (TNF- $\alpha$ ) and interleukin (IL-6) by the adipose tissue through the nuclear factor-kappa B (NF-kB) and c-jun terminal NH2-kinase (JNK) tissue specific signalling pathway [19]. Many obesity induced pathophysiologies are linked to plasminogen activator inhibitor-1 (PAI-1). Besides its role in fibrinolytic system in blood, recently it has been considered as one of the biomarkers in prediction of obesity associated diseases [20]. Elevated PAI-1 mRNA level have been found in adipose tissues from obese ob/ob/mice and also in human obesity with higher expression levels in visceral compared to subcutaneous adipose tissue depots [21,22].

\subsection{Therapeutic Options for Obesity}

Several therapeutic options approved by the FDA have been used as a short-term treatment of obesity. Noradrenergic activators such as phentermine, diethylpropion, phendimetrazine and benzphetamine cause appetite suppression and are used for less than 12 weeks in the management of obesity [23]. The most widely prescribed obesity drug between 2008-2011 was phentermine however, similar to others with a noradrenergic method of action, it can cause unpleasant side-effects such as dizziness, headache, anxiety, elevated heart rate and gastro-intestinal issues [23]. Phentermine may also be used with topiramate as a combination therapy. Topiramate is usually used as an anti-epileptic drug, but in a non-standard dose, it has shown effectiveness for weight loss. Topiramate may not be used by pregnant women due to an increased risk of oral clefts in the offspring, and side effects of this particular combination therapy include insomnia, dizziness, elevated heart rate and cognitive changes [23].

Approved by the FDA in 2012, the selective serotonin 2C receptor agonist Lorcaserin also causes appetite suppression, but has similar unpleasant side effects such as dizziness, headaches, nausea and hypoglycaemia in type 2 diabetics [23]. Another obesity drug is Orlistat. It is a reversible inhibitor of lipases; enzymes responsible for hydrolysing dietary fat in the form of triglycerides into absorbable molecules such as free fatty acid and monoglycerides. It can cause excretion of up to $30 \%$ if dietary fat but, because of its mechanism of action, it can result in unpleasant gastrointestinal side-effects if patients do not reduce their fat intake [23].

In addition to this several other anti-obesity drugs are undergoing clinical development at the moment but because of possibly hazardous side-effects and presents of high cost there is demand for more natural and safe anti-obesity drug [24].

There is strong evidence supporting the therapeutic use of polyphenols such as stilbenes, flavonoids and curcuminoids which show potential in prevention and/or treatment of obesity and its diabetic complications $[6,25,26]$. They are widely accepted in health promotion due to their antioxidant, anti-inflammatory, anti-carcinogenic, anti-obesity, anti-diabetic and anti-aging properties [2, 6, 27, 28]. The actions of their affect are believe to be through suppression of adipocyte differentiation and proliferation, inhibition of fat absorption from gut, inhibition of lipogenesis, stimulation of $\beta$-oxidation as well as inhibition of production of pro-inflammatory adipokines and stimulation of adiponectin secretion $[27,28]$.

Understanding the mechanisms leading from obesity to inflammation may have important implications for the design of novel therapies to reduce the morbidity and mortality of obesity and its associated complications. Many commonly used food compounds, such as antioxidant polyphenols, vitamins, long-chain unsaturated fatty acids, and carotenoids, have been reported to have anti-inflammatory and/or antioxidant effect resulting in reduction in weight and increase in insulin sensitivity [29]. This review discusses some of the commonly used polyphenols and their anti-inflammatory and anti-obese properties.

\subsection{Characteristics of Obesity-Induced Inflammation}

Many studies have revealed that the inflammatory state induced by metabolic surplus is in many ways different to the classic inflammation which is characterised with redness, swelling, heat and pain [1]. Although classical inflammation helps in fighting foreign invaders, obesity-induced inflammation is different in several points. The obesity-induced inflammation is metabolic in nature caused by the surplus of nutrients and that the cells which stimulate the inflammatory response are metabolic cells - adipocytes [1]. Secondly, the metabolic signals start inflammatory intracellular signalling pathways such as the kinases c-jun $\mathrm{N}$-terminal kinase (JNK), inhibitor of $\kappa$ kinase (IKK), or protein kinase $\mathrm{R}$ (PKR) that facilitate a modest, low-level 
induction of inflammatory cytokines, TNF- $\alpha$, CCL2, or Il-1 $\beta$ $[30,31]$.

Another characteristic of obesity-induced inflammation is greater infiltration of immune cells into the adipose tissue [1]. Studies have revealed that obese mice have increased macrophage population compared with lean mice $[32,33]$. More specifically the increased macrophage population would be one of proinflammatory M1 type, which has a damaging effect on insulin sensitivity [34]. Besides, the obesity-induced inflammation is characterised by its continuity, where the inflammatory pathways continue to reinforce each other, from metabolic cell signalling to immune cell responses, and it remains unresolved [1]. In conclusion, obesity-induced inflammation is linked with a reduced metabolic rate which is in contrast to the classic inflammation where we see a quite opposite-increase in metabolic rate [1].

The obesity-induced inflammation found in animal studies has been observed in humans as well. Numerous studies found induced inflammatory cytokine, increased kinase activity and macrophage infiltration in the adipose tissue of obese humans [35-37]. Furthermore, supported by strong evidence it was demonstrated that normal metabolism and proper insulin signalling are affected by activation of the inflammatory pathways and that can further result in development of insulin resistance in adipocytes [1].

One of the fundamental goals in preventing and/or combating obesity would be to ameliorate the adipocytes dysfunction which is very much present in this disorder. Targeting the inflammatory component of obesity to improve insulin sensitivity and reduce body weight is a new approach. A few promising pieces of evidence have emerged recently. Stanley et al. have shown that treatment of obese type- 2 diabetic patients with etanercept, a TNF- $\alpha$ antagonist, resulted in decreased blood glucose and increased adiponectin levels [38]. Another study used recombinant IL-1 receptor antagonist and observed improved glycaemia and increased insulin secretion from $\beta$ cell [39].

The use of anti-inflammatory nutrients, as part of an everyday diet, is a novel and promising therapeutic method in the battle with obesity and metabolic disorders [1]. Since adipose tissue inflammation is linked with the development of insulin resistance and several chronic diseases, improving adipose tissue inflammation through dietary interventions could be a useful strategy for improving the overall metabolic profile [40].

\section{Dietary Intervention to Reduce Adipose Tissue Inflammation and Insulin Resistance}

It has been widely accepted that dietary composition and not just reduction in energy intake can influence metabolic and endocrine function and overall energy balance [40, 41]. A diet rich in fruit and vegetables, recommended by many health professionals, would provide significant amounts of bioactive components, enhancing their beneficial effects mostly due to their anti-inflammatory properties [42]. Evidence shows that dietary bioactive compounds in the form of supplementation provide comparable benefits. Esfahan et al. conducted a literature review of 18 human trials with 1362 participants and found that fruit and vegetable concentrates significantly increase serum levels of antioxidant pro-vitamins and vitamins such as $\beta$-carotene and vitamins C \& E as well as folate [43].

Reduction of adipose tissue inflammation by dietary bioactive molecules could be achieved through different mechanisms either through suppression of pro-inflammatory adipokines production or stimulation of anti-inflammatory adipokines production such as adiponectin. Despite some controversy regarding adiponectin expression under different conditions, it is accepted that adiponectin is a powerful anti-inflammatory adipokine showing decreased serum level with increasing body fat. Adiponectin level is also recorded to be lower in type-2 diabetes individuals and CVD patients [44]. It has been demonstrated that chronic consumption of grape phenols resulted in reduction of obesity and related metabolic pathways as well as increased production of adiponectin [45].

\subsection{Polyphenols and Adipose Tissue Inflammation}

Naturally present in plants, polyphenols are compounds with a wide range of biological features such as anti-oxidant, anti-inflammatory, anti-thrombotic, anti-cancer, anti-obesity and anti-aging properties which enables them to display strong protective actions of many pathological conditions especially those caused by oxidative stress and/or chronic inflammation such as CVD and metabolic disorders [46-48]. Furthermore, the ability of polyphenols to suppress the growth of the adipose tissue through their antiangiogenic activity and by modulation of adipose metabolism make them very good therapeutic modulators of obesity [49].

The range and diversity of polyphenol distribution in plants have led to various forms of classification of these naturally occurring compounds. They have been categorised by their source of origin, biological function, and chemical structure. The majority of polyphenols in plants exist as glycosides with different sugar units and acylated sugar at different positions of the polyphenol skeletons. Based on the number of phenol rings present and the number and type of the structural binding element polyphenols are grouped into following classes: simple phenolic acids (fruit vegetables and grains like bran or hull); stilbenes (resveratrol); curcuminoids (turmeric); chalcones (fruit like apples); lignans (flaxseeds); flavonoids (anthocyanins from red pulp fruits); isoflavones (beans); and flavonoids (catechins). Amongst these catechins, resveratrol, curcumin, and anthocyanin rich flavonoids express very potent antioxidative and anti-inflammatory properties [27]. It has been proposed that their beneficial effect may occur through several mechanisms such as suppression of fat absorption, uptake of glucose by skeletal muscles, inhibition of 
angiogenesis in adipose tissue, inhibition of differentiation of pre-adipocytes to adipocytes, stimulation of apoptosis of mature adipocytes, and reduction of chronic inflammation associated with obesity through the regulation of adipokines production [27, 50, 51]. In addition to this, it has been found that resveratrol and curcumin alter gene expression of adipocyte specific genes and genes involved in energy metabolism and lipid accumulation respectively [49].

\subsection{Catechins and Tocopherols}

Well studied polyphenols present in green tea and cocoa (chocolate), catechins, and vitamin $\mathrm{E}$ tocopherols proved to have beneficial effect on human's health such as antioxidant and anti-inflammatory activities, anti-obesity, anti-thrombotic, cardiovascular disease and cancer prevention [27, 51-54]. Several epidemiological and clinical studies have revealed that routine intake of green tea extract is associated with low body fat and lower BMI $[55,56]$. Its anti-obesity effects are displayed through suppression of adipocyte differentiation and proliferation, inhibition of fat absorption from the gut and suppression of catechol-o-methyl transferase (COMT) [27]. Catechins intake decreases the risk of type 2 diabetes by increased glucose uptake into the skeletal muscles through up-regulating glucose transporter 4 (Glut 4) and by reducing translocation of Glut 4 and insulin levels in adipose tissues [57, 58]. In a cell model, gamma-tocopherol treatment increases the glucose uptake by skeletal muscles under induced oxidative stress as well [59].

\subsection{Resveratrol (RSV)}

A non-flavonoid polyphenol, called resveratrol, is found in grapes, red wine, peanuts and some berries such as blueberries and cranberries. RSV is recognized antioxidant and powerful anti-inflammatory molecule as well [60]. RSV has been found to be effective in inhibiting the development of several disease including CVD, diabetes, cancer, and obesity [61-63]. Several studies have revealed that RSV treatment considerably reduces adipose tissue and total body fat in high fat fed and genetically obese mice [64, 65]. Another study examining long-term consumption of RSV in rodents showed reduction in plasma triglycerides, free fatty acids, cholesterol and liver triglyceride possibly through 5'-AMP-activated protein kinase mechanisms [66].

Its anti-inflammatory effects, which result in reduction in adipose tissue inflammation, are likely achieved through suppression of NF-kB and extracellular signal-regulated kinase (ERK) activation [67]. In vivo studies demonstrate ability of RSV to attenuate high-fat diet-induced production of TNF $\alpha$ and IL- 6 and their upstream signalling molecules [68]. Furthermore, human an animal studies have revealed increase in adiponectin levels and the suppression of lipid accumulation with diet rich with RSV $[69,70]$.

Based on this evidence RSV seems to be a promising dietary bioactive molecule that can be easily encompassed into the diet to regulate adipose tissue inflammation and obesity-associated metabolic disorders.

\subsection{Curcumin}

The most studied of all curcuminoids is curcumin found in the plant turmeric and is usually used as a spice and colorant [27]. Due to its antioxidant, anti-inflammatory, anticancer, anti-angiogenesis, chemo-preventive and chemotherapeutic properties it is used in Asian medicine since the second millennium $\mathrm{BC}$ along with its wide use in research [71]. Some of the first reports dating back as much as 50-80 years ago revealed benefits of curcumin to health and its effect on liver cholesterol, weight loss as well as blood triglyceride and free fatty acids level [72]. In recent days studies have shown that curcumin indeed has significant impact on body weight, lipid metabolism, adiposity and improves obesity associated inflammation [73-75]. This is achieved through curcumin's capability to regulates several important molecules such as transcription factors, growth factors, inflammatory cytokines, protein kinases, some enzymes and several signalling pathways [76, 77]. It has been shown that two weeks of supplementation of rodent diets with 2 and $10 \mathrm{~g} / \mathrm{kg}$ of curcumin, decreases adipose tissue, reduced liver fatty acid synthesis and increases rats liver acetyl CoA oxidase activity [78]. Supplementation with $500 \mathrm{mg} / \mathrm{kg}$ of curcumin to high fat hamsters decreases the level of free fatty acids, total cholesterol, triglycerides, leptin and the insulin resistance index [79]. Furthermore, consumption of large amount of dietary curcumin by insulin resistant obese mice resulted in significant improvement of type 2 diabetes and inflammation in the liver [80].

Curcumin's anti-inflammatory properties have been reported in genetic obese (ob/ob mice) and diet-induced obesity models. Reduced macrophage infiltration into adipose tissue, increased adiponectin production, and decreased hepatic NF-KB activation [80]. Suppression of NF- $\kappa B$ resulted in suppression of TNF- $\alpha$, IL-1 $1 \beta$ and IL-6 gene expression in differentiated adipocytes [67].

The anti-inflammatory and anti-obesity properties of curcumin discussed above suggest its potential use in control of adipose tissue growth and inflammation.

\subsection{Anthocyanins}

Belonging to a family of polyphenols anthocyanins are responsible for red, purple and blue colour in plants [81]. There are 600 naturally occurring anthocyanins up to date and while they all vary slightly in the structure of their molecule they all play an important role as dietary antioxidants in the prevention of oxidative damage [82]. They also have several other biological activities, such as being an anticonvulsant, anti-carcinogenic, anti-atherosclerotic and anti-inflammatory agent, and playing a role in lowering the risk of coronary heart disease $[81,83]$.

Recent studies have reported that anthocyanins exhibit an anti-obesity effect as well and they display potency to regulate adipocyte function and adipokines expression. 
Tsuda et al. showed that anthocyanins in purple corn color made from purple corn prevent weight gain in the high-fat-diet-induced obese mice [84]. Similar results have been found in the experiment conducted by Kwon et al. where stable body weight was achieved in rats on high-fat diet (HFD) supplemented with anthocyanin from black soybeans [81]. Furthermore, serum triglycerides and cholesterol levels were significantly lower and HDL-cholesterol levels were higher in the rats fed on HFD plus black soybean anthocyanins compared with pure HFD rats [81]. This could indicate anthocyanins' possible positive effect on lipid profile.

Human adipocytes response to anthocyanins was observed by the microarray assay revealing up-regulation of adiponectin level, and down-regulation of plasminogen activator inhibitor-1 (PAI-1) and IL-6 levels [84]. Since high expression of PAI-1 and IL-6 in adipose tissue and low expression of adiponectin is connected with obesity and type-2 diabetes, regulation of their expression is an important therapeutic target for treating obesity and its relevant disorders [3].

Furthermore, Jayaprakasam et al. investigated the effect of anthocyanins on attenuation of insulin resistance in high-fat-fed $\mathrm{C} 575 \mathrm{~L} / 6$ mice. The mice were supplemented with the mixture of pure anthocyanins, cyaniding 3-O-galactoside, pelargonidin 3-O-galactoside, and delphinidin 3-O-galactoside, isolated from Cornelian cherry [85]. They found that the glucose tolerance in animals improved after 6 weeks of treatment with anthocyanins. The improvement could be seen either because the anthocyanins increased insulin sensitivity and/or increased insulin secretion [85]. In additions to these findings anthocyanins-fed mice had decreased body weight gain as well as decreased plasma cholesterol level which is in corroboration with results from two previous mentioned studies [81, 84].

Anthocyanins are broadly distributed in the human diet, and consumed in significant amount form plants on a daily basis. They have great potential for their health-promoting effect and can be used as a functional food factor. Anthocyanins have a unique therapeutic advantage due to their involvement in the regulation of the adipocyte function and may be an important factor for preventing obesity and obesity related disorders [84].

\section{Conclusions}

Obesity is a complex and multifactorial condition of chronic inflammation and oxidative stress. Although there are many diet and exercise programs for weight loss available, results are disappointing. Use of antiobesity drugs, and in extreme cases bariatric surgery, do not provide sufficient support for their efficacy. The incompetence of most of these programs is evidenced by the increase in obesity incidence and in weight regain. Novel treatments for obesity and its related diseases might be possible by targeting the production and/or action of specific adipokines, particularly those linked to inflammation. The dietary polyphenols described in this review have potential nutritional strategies for the prevention of obesity and associated inflammation as well as the increase in insulin sensitivity in diabetic people. There is still need for more in vivo research on human obese subjects to further investigate the anti-obesity and anti-inflammatory effects of polyphenol and their possible use as a novel therapeutic models in the battle with this disease.

\section{REFERENCES}

[1] Gregor MF, Hotamisligil GS. Inflammatory mechanisms in obesity. Annual review of immunology. 2011;29:415-45.

[2] Yun JW. Possible anti-obesity therapeutics from nature--a review. Phytochemistry. 2010;71(14-15):1625-41.

[3] Dimitrova R, Petkova V, Dimitrov M, Madzharov V, Nikolova I, Petkova E, et al. Obesity-Relationship with Vascular Dysfunction. Annals of Nutrition and Metabolism. 2014; 1(1):6.

[4] de Onis M, Blossner M, Borghi E. Global prevalence and trends of overweight and obesity among preschool children. The American journal of clinical nutrition. 2010; 92(5): 1257-64.

[5] http://www.who.int/features/factfiles/obesity/en/.

[6] Wang S, Moustaid-Moussa N, Chen L, Mo H, Shastri A, Su R, et al. Novel insights of dietary polyphenols and obesity. The Journal of nutritional biochemistry. 2014;25(1):1-18.

[7] Tsuda T, Horio F, Uchida K, Aoki H, Osawa T. Dietary cyanidin 3-O-beta-D-glucoside-rich purple corn color prevents obesity and ameliorates hyperglycemia in mice. The Journal of nutrition. 2003;133(7):2125-30.

[8] Hotamisligil GS. Inflammation and metabolic disorders. Nature. 2006; 444(7121):860-7.

[9] Trayhurn P, Wood IS. Signalling role of adipose tissue: adipokines and inflammation in obesity. Biochemical Society transactions. 2005;33(Pt 5):1078-81.

[10] Dalmas E, Clement K, Guerre-Millo M. Defining macrophage phenotype and function in adipose tissue. Trends in immunology. 2011;32(7):307-14.

[11] Hotamisligil GS, Shargill NS, Spiegelman BM. Adipose expression of tumor necrosis factor-alpha: direct role in obesity-linked insulin resistance. Science. 1993; 259(5091): 87-91.

[12] Shoelson SE, Lee J, Goldfine AB. Inflammation and insulin resistance. The Journal of clinical investigation. 2006; 116(7): 1793-801.

[13] Berg AH, Scherer PE. Adipose tissue, inflammation, and cardiovascular disease. Circulation research. 2005; 96(9): 939-49.

[14] Cai D, Yuan M, Frantz DF, Melendez PA, Hansen L, Lee J, et al. Local and systemic insulin resistance resulting from 
hepatic activation of IKK-beta and NF-kappaB. Nature medicine. 2005;11(2):183-90.

[15] Ehses JA, Perren A, Eppler E, Ribaux P, Pospisilik JA, Maor-Cahn R, et al. Increased number of islet-associated macrophages in type 2 diabetes. Diabetes. 2007; 56(9): 2356-70.

[16] De Souza CT, Araujo EP, Bordin S, Ashimine R, Zollner RL, Boschero AC, et al. Consumption of a fat-rich diet activates a proinflammatory response and induces insulin resistance in the hypothalamus. Endocrinology. 2005;146(10):4192-9.

[17] Saghizadeh M, Ong JM, Garvey WT, Henry RR, Kern PA. The expression of TNF alpha by human muscle. Relationship to insulin resistance. The Journal of clinical investigation. 1996; 97(4):1111-6.

[18] Pickup JC. Inflammation and activated innate immunity in the pathogenesis of type 2 diabetes. Diabetes care. 2004; 27(3): 813-23.

[19] Bastard JP, Maachi M, Lagathu C, Kim MJ, Caron M, Vidal $\mathrm{H}$, et al. Recent advances in the relationship between obesity, inflammation, and insulin resistance. European cytokine network. 2006;17(1):4-12.

[20] Zagotta I, Dimova EY, Funcke JB, Wabitsch M, Kietzmann T, Fischer-Posovszky P. Resveratrol suppresses PAI-1 gene expression in a human in vitro model of inflamed adipose tissue. Oxidative medicine and cellular longevity. 2013;2013:793525.

[21] Samad F, Loskutoff DJ. Tissue distribution and regulation of plasminogen activator inhibitor-1 in obese mice. Mol Med. 1996;2(5):568-82.

[22] Cigolini M, Targher G, Bergamo Andreis IA, Tonoli M, Agostino G, De Sandre G. Visceral fat accumulation and its relation to plasma hemostatic factors in healthy men. Arteriosclerosis, thrombosis, and vascular biology. 1996;16(3):368-74.

[23] Yanovski SZ, Yanovski JA. Long-term drug treatment for obesity: a systematic and clinical review. Jama. 2014;311(1):74-86.

[24] Rodgers RJ, Tschop MH, Wilding JP. Anti-obesity drugs: past, present and future. Disease models \& mechanisms. 2012;5(5):621-6.

[25] Pietta PG. Flavonoids as antioxidants. Journal of natural products. 2000;63(7):1035-42.

[26] Middleton E, Jr., Kandaswami C, Theoharides TC. The effects of plant flavonoids on mammalian cells: implications for inflammation, heart disease, and cancer. Pharmacological reviews. 2000;52(4):673-751.

[27] Meydani M, Hasan ST. Dietary polyphenols and obesity. Nutrients. 2010;2(7):737-51.

[28] Siriwardhana N, Kalupahana NS, Cekanova M, LeMieux M, Greer B, Moustaid-Moussa N. Modulation of adipose tissue inflammation by bioactive food compounds. The Journal of nutritional biochemistry. 2013;24(4):613-23.

[29] Puglisi MJ, Fernandez ML. Modulation of C-reactive protein, tumor necrosis factor-alpha, and adiponectin by diet, exercise, and weight loss. The Journal of nutrition. 2008; 138(12): 2293-6.
[30] Solinas G, Karin M. JNK1 and IKKbeta: molecular links between obesity and metabolic dysfunction. FASEB journal : official publication of the Federation of American Societies for Experimental Biology. 2010;24(8):2596-611.

[31] Nakamura T, Furuhashi M, Li P, Cao H, Tuncman G, Sonenberg N, et al. Double-stranded RNA-dependent protein kinase links pathogen sensing with stress and metabolic homeostasis. Cell. 2010;140(3):338-48.

[32] Xu H, Barnes GT, Yang Q, Tan G, Yang D, Chou CJ, et al. Chronic inflammation in fat plays a crucial role in the development of obesity-related insulin resistance. The Journal of clinical investigation. 2003;112(12):1821-30.

[33] Weisberg SP, McCann D, Desai M, Rosenbaum M, Leibel RL, Ferrante AW, Jr. Obesity is associated with macrophage accumulation in adipose tissue. The Journal of clinical investigation. 2003;112(12):1796-808.

[34] Olefsky JM, Glass CK. Macrophages, inflammation, and insulin resistance. Annual review of physiology. 2010; 72: 219-46.

[35] Hotamisligil GS, Arner P, Caro JF, Atkinson RL, Spiegelman BM. Increased adipose tissue expression of tumor necrosis factor-alpha in human obesity and insulin resistance. The Journal of clinical investigation. 1995;95(5):2409-15.

[36] Harman-Boehm I, Bluher M, Redel H, Sion-Vardy N, Ovadia $\mathrm{S}$, Avinoach E, et al. Macrophage infiltration into omental versus subcutaneous fat across different populations: effect of regional adiposity and the comorbidities of obesity. The Journal of clinical endocrinology and metabolism. 2007;92(6):2240-7.

[37] Bashan N, Dorfman K, Tarnovscki T, Harman-Boehm I, Liberty IF, Bluher M, et al. Mitogen-activated protein kinases, inhibitory-kappaB kinase, and insulin signaling in human omental versus subcutaneous adipose tissue in obesity. Endocrinology. 2007;148(6):2955-62.

[38] Stanley TL, Zanni MV, Johnsen S, Rasheed S, Makimura H, Lee H, et al. TNF-alpha antagonism with etanercept decreases glucose and increases the proportion of high molecular weight adiponectin in obese subjects with features of the metabolic syndrome. The Journal of clinical endocrinology and metabolism. 2011;96(1):E146-50.

[39] Larsen CM, Faulenbach M, Vaag A, Volund A, Ehses JA, Seifert B, et al. Interleukin-1-receptor antagonist in type 2 diabetes mellitus. The New England journal of medicine. 2007;356(15):1517-26.

[40] Kalupahana NS, Claycombe KJ, Moustaid-Moussa N. (n-3) Fatty acids alleviate adipose tissue inflammation and insulin resistance: mechanistic insights. Adv Nutr. 2011;2(4):304-16.

[41] Djuric Z. The Mediterranean diet: effects on proteins that mediate fatty acid metabolism in the colon. Nutrition reviews. 2011;69(12):730-44.

[42] Rosa FT, Zulet MA, Marchini JS, Martinez JA. Bioactive compounds with effects on inflammation markers in humans. International journal of food sciences and nutrition. 2012;63(6):749-65.

[43] Esfahani A, Wong JM, Truan J, Villa CR, Mirrahimi A, Srichaikul K, et al. Health effects of mixed fruit and vegetable concentrates: a systematic review of the clinical interventions. 
Journal of the American College of Nutrition. 2011;30(5):285-94.

[44] Fantuzzi G. Adiponectin and inflammation: consensus and controversy. The Journal of allergy and clinical immunology. 2008;121(2):326-30

[45] Decorde K, Teissedre PL, Sutra T, Ventura E, Cristol JP, Rouanet JM. Chardonnay grape seed procyanidin extract supplementation prevents high-fat diet-induced obesity in hamsters by improving adipokine imbalance and oxidative stress markers. Molecular nutrition \& food research. 2009;53(5):659-66.

[46] Link A, Balaguer F, Goel A. Cancer chemoprevention by dietary polyphenols: promising role for epigenetics. Biochemical pharmacology. 2010;80(12):1771-92.

[47] Bakker GC, van Erk MJ, Pellis L, Wopereis S, Rubingh CM, Cnubben $\mathrm{NH}$, et al. An antiinflammatory dietary mix modulates inflammation and oxidative and metabolic stress in overweight men: a nutrigenomics approach. The American journal of clinical nutrition. 2010;91(4):1044-59.

[48] Singh I, Mok M, Christensen AM, Turner AH, Hawley JA. The effects of polyphenols in olive leaves on platelet function. Nutrition, metabolism, and cardiovascular diseases : NMCD. 2008;18(2):127-32.

[49] Lin JK, Lin-Shiau SY. Mechanisms of hypolipidemic and anti-obesity effects of tea and tea polyphenols. Molecular nutrition \& food research. 2006;50(2):211-7.

[50] Lin J, Della-Fera MA, Baile CA. Green tea polyphenol epigallocatechin gallate inhibits adipogenesis and induces apoptosis in 3T3-L1 adipocytes. Obesity research. 2005; 13(6):982-90

[51] Murphy KJ, Chronopoulos AK, Singh I, Francis MA, Moriarty H, Pike MJ, et al. Dietary flavanols and procyanidin oligomers from cocoa (Theobroma cacao) inhibit platelet function. The American journal of clinical nutrition. 2003;77(6):1466-73.

[52] Singh I, Quinn H, Mok M, Southgate RJ, Turner AH, Li D, et al. The effect of exercise and training status on platelet activation: do cocoa polyphenols play a role? Platelets. 2006;17(6):361-7.

[53] Singh I, Turner AH, Sinclair AJ, Li D, Hawley JA. Effects of gamma-tocopherol supplementation on thrombotic risk factors. Asia Pacific journal of clinical nutrition. 2007;16(3):422-8.

[54] Vucinic L, Singh I, Spargo FJ, Hawley JA, Linden MD. Gamma tocopherol supplementation prevents exercise induced coagulation and platelet aggregation. Thrombosis research. 2010;125(2):196-9.

[55] Hughes LA, Arts IC, Ambergen T, Brants HA, Dagnelie PC, Goldbohm RA, et al. Higher dietary flavone, flavonol, and catechin intakes are associated with less of an increase in BMI over time in women: a longitudinal analysis from the Netherlands Cohort Study. The American journal of clinical nutrition. 2008;88(5):1341-52.

[56] Nagao T, Komine Y, Soga S, Meguro S, Hase T, Tanaka Y, et al. Ingestion of a tea rich in catechins leads to a reduction in body fat and malondialdehyde-modified LDL in men. The American journal of clinical nutrition. 2005;81(1):122-9.
[57] Hosoda K, Wang MF, Liao ML, Chuang CK, Iha M, Clevidence B, et al. Antihyperglycemic effect of oolong tea in type 2 diabetes. Diabetes care. 2003;26(6):1714-8.

[58] Ashida H, Furuyashiki T, Nagayasu H, Bessho H, Sakakibara $\mathrm{H}$, Hashimoto $\mathrm{T}$, et al. Anti-obesity actions of green tea: possible involvements in modulation of the glucose uptake system and suppression of the adipogenesis-related transcription factors. Biofactors. 2004;22(1-4):135-40.

[59] Singh I, Carey AL, Watson N, Febbraio MA, Hawley JA. Oxidative stress-induced insulin resistance in skeletal muscle cells is ameliorated by gamma-tocopherol treatment. European journal of nutrition. 2008;47(7):387-92.

[60] Burns J, Yokota T, Ashihara H, Lean ME, Crozier A. Plant foods and herbal sources of resveratrol. Journal of agricultural and food chemistry. 2002;50(11):3337-40.

[61] Hung LM, Chen JK, Huang SS, Lee RS, Su MJ. Cardioprotective effect of resveratrol, a natural antioxidant derived from grapes. Cardiovascular research. 2000; 47(3): 549-55.

[62] Atten MJ, Godoy-Romero E, Attar BM, Milson T, Zopel M, Holian O. Resveratrol regulates cellular PKC alpha and delta to inhibit growth and induce apoptosis in gastric cancer cells. Investigational new drugs. 2005;23(2):111-9.

[63] Zang M, Xu S, Maitland-Toolan KA, Zuccollo A, Hou X, Jiang B, et al. Polyphenols stimulate AMP-activated protein kinase, lower lipids, and inhibit accelerated atherosclerosis in diabetic LDL receptor-deficient mice. Diabetes. 2006;55(8): 2180-91.

[64] Macarulla MT, Alberdi G, Gomez S, Tueros I, Bald C, Rodriguez VM, et al. Effects of different doses of resveratrol on body fat and serum parameters in rats fed a hypercaloric diet. Journal of physiology and biochemistry. 2009; 65(4): 369-76.

[65] Shang J, Chen LL, Xiao FX, Sun H, Ding HC, Xiao H. Resveratrol improves non-alcoholic fatty liver disease by activating AMP-activated protein kinase. Acta pharmacologica Sinica. 2008;29(6):698-706.

[66] Rivera L, Moron R, Zarzuelo A, Galisteo M. Long-term resveratrol administration reduces metabolic disturbances and lowers blood pressure in obese Zucker rats. Biochemical pharmacology. 2009;77(6):1053-63.

[67] Gonzales AM, Orlando RA. Curcumin and resveratrol inhibit nuclear factor-kappaB-mediated cytokine expression in adipocytes. Nutrition \& metabolism. 2008;5:17.

[68] Kim S, Jin Y, Choi Y, Park T. Resveratrol exerts anti-obesity effects via mechanisms involving down-regulation of adipogenic and inflammatory processes in mice. Biochemical pharmacology. 2011;81(11):1343-51.

[69] Olholm J, Paulsen SK, Cullberg KB, Richelsen B, Pedersen SB. Anti-inflammatory effect of resveratrol on adipokine expression and secretion in human adipose tissue explants. Int J Obes (Lond). 2010;34(10):1546-53.

[70] Ahn J, Cho I, Kim S, Kwon D, Ha T. Dietary resveratrol alters lipid metabolism-related gene expression of mice on an atherogenic diet. Journal of hepatology. 2008;49(6):1019-28.

[71] Sharma RA, Gescher AJ, Steward WP. Curcumin: the story 
so far. Eur J Cancer. 2005;41(13):1955-68.

[72] Rao DS, Sekhara NC, Satyanarayana MN, Srinivasan M. Effect of curcumin on serum and liver cholesterol levels in the rat. The Journal of nutrition. 1970;100(11):1307-15.

[73] Ejaz A, Wu D, Kwan P, Meydani M. Curcumin inhibits adipogenesis in 3T3-L1 adipocytes and angiogenesis and obesity in C57/BL mice. The Journal of nutrition. 2009; 139(5):919-25.

[74] Tang Y, Chen A. Curcumin protects hepatic stellate cells against leptin-induced activation in vitro by accumulating intracellular lipids. Endocrinology. 2010;151(9):4168-77.

[75] Alappat L, Awad AB. Curcumin and obesity: evidence and mechanisms. Nutrition reviews. 2010;68(12):729-38.

[76] Zhou H, Beevers CS, Huang S. The targets of curcumin. Current drug targets. 2011;12(3):332-47.

[77] Aggarwal BB, Shishodia S. Molecular targets of dietary agents for prevention and therapy of cancer. Biochemical pharmacology. 2006;71(10):1397-421.

[78] Asai A, Miyazawa T. Dietary curcuminoids prevent high-fat diet-induced lipid accumulation in rat liver and epididymal adipose tissue. The Journal of nutrition. 2001; 131(11): 2932-5.

[79] Jang EM, Choi MS, Jung UJ, Kim MJ, Kim HJ, Jeon SM, et al. Beneficial effects of curcumin on hyperlipidemia and insulin resistance in high-fat-fed hamsters. Metabolism: clinical and experimental. 2008;57(11):1576-83.

[80] Weisberg SP, Leibel R, Tortoriello DV. Dietary curcumin significantly improves obesity-associated inflammation and diabetes in mouse models of diabesity. Endocrinology. 2008;149(7):3549-58.

[81] Kwon SH, Ahn IS, Kim SO, Kong CS, Chung HY, Do MS, et al. Anti-obesity and hypolipidemic effects of black soybean anthocyanins. Journal of medicinal food. 2007;10(3):552-6.

[82] Prior RL, Wu X. Anthocyanins: structural characteristics that result in unique metabolic patterns and biological activities. Free radical research. 2006;40(10):1014-28.

[83] Tsoyi K, Park HB, Kim YM, Chung JI, Shin SC, Lee WS, et al. Anthocyanins from black soybean seed coats inhibit UVB-induced inflammatory cylooxygenase-2 gene expression and PGE2 production through regulation of the nuclear factor-kappaB and phosphatidylinositol 3-kinase/Akt pathway. Journal of agricultural and food chemistry. 2008;56(19):8969-74.

[84] Tsuda T. Regulation of adipocyte function by anthocyanins; possibility of preventing the metabolic syndrome. Journal of agricultural and food chemistry. 2008;56(3):642-6.

[85] Jayaprakasam B, Olson LK, Schutzki RE, Tai MH, Nair MG. Amelioration of obesity and glucose intolerance in high-fat-fed C57BL/6 mice by anthocyanins and ursolic acid in Cornelian cherry (Cornus mas). Journal of agricultural and food chemistry. 2006;54(1):243-8. 